\title{
On Application of Experience-based Teaching Mode in Tourism Management Teaching
}

\author{
Lan $\mathrm{Xia}^{1}$, Juan Wang ${ }^{1}$ \\ ${ }^{1}$ Department of Tourism, Vocational College, Sichuan Radio and TV University, Chengdu, 610107, \\ China
}

Keywords: Tourism management. Teaching. Experience-based teaching

\begin{abstract}
During teaching students of tourism management major, the application of experience-based teaching mode is of great significance. Greatly influenced by traditional educational concept, the teaching mode of tourism management major still adopts teacher-dominated traditional mode. Such mode restricts cultivation of tourism management personnel. Experience-based teaching mode is "student-centered". In the teaching process, teachers mainly guide students to gain knowledge through personal experience. Such teaching mode can effectively improve teaching effects during teaching students of tourism management major.
\end{abstract}

\section{Foreword}

At present, tourism develops faster and faster, and the requirements for practitioners improve continuously. Colleges should innovate for the teaching mode during cultivating tourism management personnel and enhance practical teaching in a bid to cultivate high-quality inter-disciplinary talents complying with demands of tourism. Experience-based teaching mode is a process of guiding students for practice, fully mobilizing their thinking and emotion, experiencing and understanding knowledge and skills in practice and finally proficiently mastering knowledge. Such teaching mode has important significance for colleges to cultivate high-quality personnel. Learning in practice is the core idea and main teaching means of experience-based teaching. This idea or method needs to be implemented in teaching.

\section{Significance of experience-based teaching tourism management teaching practice}

In the teaching process, experience-based teaching sets up contextual mode according to teaching objectives and teaching contents of tourism management course and makes students fully mobilize their emotion in virtual practice and actively construct knowledge. Meanwhile, students' professional ability is also trained.

\section{Tourism management major needs experience-based teaching}

Currently, college education of tourism management major is directly connected to tourist industry in society. The subject features are very distinctive. Students' practical ability and processional skills are paid attention to in the teaching process. Practical teaching is an indispensable and important link for helping students to improve professional skills in teaching tourism management major. It is a process of testing, verifying and thinking theoretical knowledge learned by students in social practice. Such feature of experience-based teaching reflects the objective to cultivate students' operation ability. In addition, the guiding ideology of experience-based teaching is to establish the leading position of students in the teaching process and highlight the guiding function of teachers in the teaching activities. This teaching idea breaks previous traditional mode which attaches importance to theoretical learning and neglects cultivation of students' ability and solves such problems that practical teaching effects are not obvious under traditional mode and students are difficulty to satisfy social post requirements. Thus, it has important significance for changing laggard practical teaching of tourism management major. So, the application of experience-based teaching mode can effectively boost practical teaching effects in tourism management teaching. 


\section{Motivate students' learning enthusiasm}

The application of experience-based teaching mode changes previous traditional cramming-type teaching mode of "teachers' teaching and students' reception". Compared with traditional teacher-dominated teaching mode, experience-based teaching mode further stresses students' initiative in learning process. Experience-based teaching mode regards students as the subject of teaching activities and fully motivates their learning enthusiasm. In this teaching mode, students mobilize their emotions, practice and complete learning process under the guidance of teachers. Improving students' participation can motivate their learning enthusiasm, contributes to students to experience the joys of cooperation, independent creation and active learning and make the teaching activity is an autonomous experience process full of joys rather than passive reception. So, the teaching objectives can be realized more easily.

\section{Beneficial to teachers and students to learn from each other}

The application of experience-based teaching makes teachers enter students, enhances exchange between teachers and students and promotes formation of equal and harmonious relationship between teachers and students. Meanwhile, in the good atmosphere jointly established by teachers and students, mutual comprehension and tolerance are enhanced. Since there are differences among students, different students have different feelings for the same problems. So, teachers need to give play to their guiding function, help students with their rich experience and knowledge and make sure students' experience learning proceeds in the correct direction. Moreover, the teaching effects of experience-based teaching depend on selection of experience items and setting of teaching situations to s large extent. Besides, higher requirements for teachers to control the classroom are proposed. So, the application of experience-based teaching mode promotes teachers to continuously improve their teaching level. It thus ca be said that experience-based teaching is beneficial to teachers and students to learn from each other.

\section{Application of experience-based teaching mode}

Experience-based teaching mode develops from experience-based learning mode. As early as 1984, David·Kolb proposed this concept in his book Experience-based Learning Mode. In his opinion, experience-based learning is a multi-dimension process. Learners will experience the following four stages: specific experience; observation and introspection; formation of abstract concept; practical experience. In this process, learners first enter a new situation, rethink their experience, then reduce the experience observed and understood to logical concrete concept, finally test their ideas in practice and apply their ideas in real life. Through analysis of application situation of experience-based teaching mode in tourism management major, this paper divides the experience-based teaching process into four stages as follows:

\section{Design and preparation before class}

In this stage, teachers need to prepare lessons. Teachers should combine course contents and requirements of teaching program to collect materials in language, scene and application situation, design experience situation and set students' learning tasks. In this stage, the quality and contents of experience situations designed by teachers have the direct bearing on effects of experience-based teaching. During setting the situations, multiple methods should be utilized such as role play, operation, demonstration, environmental layout and physical display.

\section{Situational experience}

In this stage, teachers guide students to experience practical situations designed in advance. When the teaching starts, teachers need to introduce the setting background of the situation, theoretical knowledge points to be learned and detailed operation flow. In experience-based teaching idea, students' learning efficiency can be ensured under the precondition of active participation in situational experience. Furthermore, good teaching effects should be based on correctly guiding students' experience activities by teachers. Only in this way, students can actively construct knowledge framework. It thus can be seen that the realization of the objective of experience-based teaching and improvement of teaching effects need students to motivate enthusiasm and input 
emotion in the experience process. Thus, in the link of situational experience, teachers should gear to actual circumstances, guide students to independently study related contents, encourage them to actively open their mouth and boldly participate and cultivate their creative thinking mode and professional practical ability. In addition, teachers should accurately master students' mood in the experience- process, actively communicate with them and control the direction. In this process, teachers should care for, approve and trust students. When students run into difficulties, teachers should provide relevant help, guide them to gradually form self-evaluation ability and create freer experience environment.

\section{Initiative practice}

In this link, after students experience the situation, they autonomously conclude the knowledge learned in the experience link and apply the knowledge in practice. There are many ways for initiative practice. Teachers may set relevant practical tasks or arrange assignments; or teachers set training courses according to teaching practice objectives; or students carry out social practical activities in enterprises. Students' initiative practice process is also a process of deepening and understanding the knowledge learned. In this process, it is required to stick to the principle of students giving play to initiative and teachers conducting guidance and supervision and ensure the subject status of students in practice. Teachers should guide students to complete tasks according to the correct flow in initiative practice and meanwhile pay attention to students' information feedback. Teachers should timely discover and solve problems and control the schedule with inspection and question-asking methods.

\section{Teaching evaluation}

Teaching evaluation aims to assess teachers' teaching effects and examine students' learning effects. This link has important significance for promoting effects of experience-based teaching. Experience-based teaching is one type of quality-oriented education. So, teaching evaluation is required according to rational and scientific evaluation criteria. Traditional evaluation mode is dominated by scores. The leading factor is too single. It is hard to objectively reflect the effects, status and effects of intangible factors such as emotion and willpower in teaching activities. So, teachers should hold more rational attitude to scores. Meanwhile, it is required to establish multi-evaluation criteria, synthesize teachers' evaluation, peer assessment and students' self-evaluation so as to boost the status of experience process in the teaching evaluation. It's worth noting that teachers serve as the organizers of teaching activities and students' guides in experience-based teaching mode, different from previous teacher-dominated teaching mode. When teachers evaluate teaching effects, they should consider the effectiveness of teaching situations, whether the situations mobilize students' learning enthusiasm and whether they full help and guide students to comprehend the theories and concepts.

\section{Methods to implement experience-based teaching mode for tourism management major}

\section{Experience-based teaching method}

Firstly, case teaching. This teaching method means teachers select typical cases in a field in tourist industry according to specific teaching objective and guide students to analyze the cases so as to make them master related knowledge points and competence requirements in the cases. Then, teachers lead students to enter the teaching situation chosen in advance and make them actively think and analyze. In this way, students can deepen understanding of knowledge, train their professional skills and cultivate analytical ability and problem-solving ability in the experience process.

Secondly, role play. Such teaching method means in the teaching activities, teachers set a specific contextual mode in which students play different roles and comprehend teaching contents in the experience process. Take tour guide business for example. When role play method is used for experience-based teaching, students can be grouped and members of every group act tour guides and tourists in turn. In the process of role exchange, students can deepen the feeling of tourist guide service skills and methods and know the requirements of tourists for tourist guide services. 
Thirdly, discussion experience teaching. In such teaching method, teachers arrange discussion situations in advance and let students independently discuss a topic in groups. In the free discussion environment, students can boldly express their opinions, reach a consensus on a viewpoint during exchange with others and meanwhile reserve individual opinions. For example, when teaching admission ticket management for scenic spots, teachers can require students discussing admission ticket problems of a scenic spot and analyzing whether the admission ticket of the scenic spot should boost, the degree and causes. In this way, students have visual cognition of admission ticket pricing principle of scenic spots in the discussion process.

Fourthly, field experience-based teaching. In this teaching method, students are led into real tourist environment such as practical scenic spots and shopping places, and teachers guide students to learn related tourism knowledge. Such teaching method breaks through special limitation of traditional teaching mode, solves baldness of blackboard-writing teaching and effectively motivates students' learning enthusiasms. For instance, when teaching service management in hotel management, after teachers teach basic contents of service management, they can lead students into the hotel and let them communicate with the personnel. Students can deepen comprehension of teaching contents through consulting the personnel and combing the theoretical knowledge learned. This can also help students accumulate experience for future work.

\section{To increase teaching input and set up training bases}

At present, the requirements for the personnel in tourism management major in terms of practical operation become increasingly high. So, it is very necessary for colleges to set up relevant training bases. Many colleges have set up the simulation laboratory, such as simulated travel agency, simulated tour guide training room, simulated dining room and simulated guest room. But it is very hard for these laboratories to be really similar to real scenic spots due to fund limitation. It is also difficult to ensure students' experience. Thus, colleges should establish cooperation relationship with related enterprises and set up training bases so as to lay a good foundation for improving students; professional skills.

\section{To boost teachers' professional quality}

Under experience-based teaching mode, teachers' status transforms to current teaching organizers and guides from traditional leading role. So, teachers need to meet higher requirements in the aspect of practical ability. They not just should own perfect theoretical knowledge, but also need strong practical ability in order to guide students to experience smoothly.

\section{Conclusions}

In practical application, enough time is still needed to form perfect teaching system for experience-based teaching mode. According to current situations, the effect of this teaching mode on teaching of tourism management major has preliminarily appeared. It is still necessary to continuously explore and perfect such teaching mode in practical teaching activities.

\section{References}

[1] Tang Zhiyuan: Analysis of experience teaching mode based on objective management - taking tourism management major for example, Pioneering with Science \& Technology Monthly, 2013(3)

[2] Jia Yanju: On experience-based teaching mode for tourism management major - taking teaching reform of Tour Guide Business for example, Journal of Shandong Education Institute, 2008(6)

[3] Liu Cang: Application of experience-based teaching mode in tourism management major, Journal of Educational Institute of Jilin Province (subject), 2010(5)

[4] Li Zhendong, Huang Jing: Analysis of experience-based teaching mode in tourism management major, Journal of Inner Mongolia Agricultural University (social sciences), 2010(8) 
[5] Liu Huizhen: Construction of personnel experience-based cultivation mode for tourism management major, Legal \& Economy (middle), 2013(5)

[6] Sun Fei: Application of multi-mode experience teaching in tourism management teaching practice in higher vocational education, Estate and Science Tribune, 2010(9)

[7] Ma Qiaohui: Exploration of experience-based teaching mode for tourism management major, Journal of Sichuan Higher Institute of Cuisine, 2012(11) 